\title{
Edible Ectomycorrhizal Mushrooms: A Non-Timber Forest Product of Neotropical Forests and its Relation to Sustainability and Climate Change Mitigation
}

\author{
Perez-Moreno J. *, Hernandez-Santiago F. and Martínez-Reyes M. \\ Microbiologia, Edafologia, Campus Montecillo, Colegio de Postgraduados, Mexico \\ *jperezm@colpos.mx
}

\begin{abstract}
Edible ectomycorrhizal mushrooms (EEM) are a non-timber forest product that constitutes a valuable genetic resource and a nutritious and functional food containing antitumor, antidiabetes, antimicrobial, antihypertensive and antioxidant bioactive compounds, whose sustainable use can contribute to conservation of Neotropical forests. International commerce of some EEM annually is worth billions of dollars, while numerous EEM species represent a valuable food resource and an important source of income for thousands of families in countries with developing economies. Additionally, EEM can be used as biofertilizers which increase nutrient mobilization, health and survival of trees, therefore contributing to successful reforestations. The cultivation of some species of EEM has already been achieved, as in the case of the black truffles in Europe, while efforts in order to cultivate other species currently is being developed in different countries. During the last two decades, ethnomycological and biotechnological research registering EEM consumed in Mexico and selecting species feasible to inoculate Neotropical trees has been conducted by the authors. More than 250 EEM species have been recorded to be consumed as traditional food by 23 ethnic groups in the country; accounting for the second largest biodiversity of EEM worldwide, only after China. The sustainable use of EEM constitutes an important component of forest management, particularly in Neotropical areas with high degree of economic and social margination. Additionally, 25 species of EEM have been tested by the authors e.g. Laccaria, Hebeloma and Suillus species showing increased macro-( $\mathrm{N}, \mathrm{P}, \mathrm{K}, \mathrm{Ca}$ and $\mathrm{Mg}$ ) and micro-(Fe and $\mathrm{Ca}$ ) nutrient mobilization, photosynthetic rate and chlorophyll $\mathrm{a}, \mathrm{b}$ and total contents of inoculated plants compared with non-inoculated plants. Conspicuous ectomycorrhizal colonization, up to $100 \%$ in some cases, and production of EEM sporomes with 20 tested pine and oak species have demonstrated the feasibility of this biotechnology. Field trials developed in both low- and high-fertility soils have demonstrated increases in the survival of native inoculated pines and oaks; and initial production of EEM sporomes four years after the establishment of tree plantations has occurred. Molecular and metagenomic sequencing of the rRNA S1 and S18 genes studies conducted by the authors, have shown the persistence of the inoculated EEM and conspicuous changes in the microbiomes associated with mycorrhized and non-mycorrized root trees, respectively. This biotechnology has shown to increase natural production of EEM, demonstrating benefits to sustainable ecosystem management and, through successful reforestations, to mitigation of climate change.
\end{abstract}

Keywords: Biodiversity conservation, Edible wild mushrooms, Ectomycorrhiza, Non-timber forest products, Environmental sustainability

Proceedings of the International Forestry and Environment Symposium 2016, Department of Forestry and Environmental Science, University of Sri Jayewardenepura, Sri Lanka.

6 